\title{
Oficina da história no ciberespaço
}

History workshop in cyberspace

Anita Lucchesi*

\section{Maynard, Dilton Cândido Santos}

Escritos sobre história e internet

Rio de Janeiro: Fapitec; Multifoco, 2011. 152p.

Uma das mais belas apresentações de livros que já li começava assim: "Apresentar um livro é fazê-lo presente". Ora, mas não é óbvio? Contudo, continua argutamente o autor: "Mas, qual poderia ser seu presente? O da escritura, que já não é, ou o da leitura, que ainda não é?”. Repito as palavras e questionamentos de Jorge Larrosa ${ }^{1}$ pensando na velocidade com que se transformam as paisagens da seara em que Dilton Maynard decidiu se enveredar ao eleger como tema central de seu livro as relações entre história e internet.

Sendo assim, a obra Escritos sobre história e internet chama a atenção por um particular interesse pelo tema dos ambientes telemáticos e provoca, em virtude disso, certo conforto antecipado em, ao menos, podermos esperar que sua leitura abrace as discussões sobre o elemento digital e suas implicações para o nosso métier, historicamente analógico e papirofílico. Assim, recomendo o livro desejando que as presenças que dele fizerem, consoantes ou dissonantes à minha, venham incrementar o debate acerca deste Novo Mundo para onde as agitadas águas do ciberespaço nos levam. Por enquanto navegamos à deriva.

O breve mas consistente volume de Maynard se apresenta nos moldes de um pequeno códex, composto por quatro artigos que foram escritos em momentos distintos e posteriormente linkados uns aos outros sob a tag dos problemas que a internet traz para o dia a dia da Oficina da História. Decerto o livro não pretende esgotar o assunto, mas sim, apresentar reflexões e propor

\footnotetext{
* Mestranda, Programa de Pós-Graduação em História Comparada, Universidade Federal do Rio de Janeiro. Largo de São Francisco de Paula no 1, sala 311, Centro. 20051-070 Rio de Janeiro - RJ - Brasil.anita.lucchesi@gmail.com
} 
questionamentos de caráter introdutório que possam, em um horizonte augurável, ser desdobrados mais à frente por outros pesquisadores. Mesmo porque a publicação é uma cápsula de perguntas, um convite a novas investigações sobre a internet e através dela. Aliás, a grande pergunta do livro talvez seja justamente aquela não dita, mas todo o tempo presente no background dessa leitura: “Afinal, por que não trabalhar com internet?".

Para evidenciar como a internet pode ser um objeto-problema e também uma ferramenta-problema para os historiadores do nosso século, Maynard primeiro nos apresenta o que é essa tal Rede Mundial de Computadores, para depois trazer alguns casos de estudos resultantes de sua experiência com a internet nos últimos anos e pesquisas que vem realizando nessa área.

No capítulo de abertura, o autor esboça uma breve história da internet. Descreve a trajetória dessa inovadora tecnologia, pontuando, sobretudo, quais foram as circunstâncias históricas que favoreceram seu surgimento. Apresenta a emergência da internet como um produto do seu tempo, de demandas sociais específicas e condições propícias para o desenvolvimento de seu caráter aberto, descentralizado e colaborativo. Características que se acentuaram principalmente a partir da década de 1990, depois que a rede se libertou dos grilhões de sua missão como tecnologia militar do Departamento de Defesa norte-americano e começou a ser viabilizada também para fins comerciais.

Segundo Maynard, professor de História Contemporânea da Universidade Federal de Sergipe (UFS) e orientador de diversos trabalhos sobre cibercultura, intolerância e extrema-direita na internet, teriam sido o cenário bipolarizado da Guerra Fria e, concomitantemente, o ambiente descentralizado dos protestos pacifistas e contraculturais das décadas de 1960 e 1970 a proporcionarem as condições ideais para o surgimento e desenvolvimento da 'rede das redes'. Para o autor, “a verdadeira questão não é ser contra ou a favor da internet. O importante é compreender as suas mudanças qualitativas” (p.42).

É nessa esteira que o autor segue apresentando outros três principais filões por onde tem espreitado as implicações da internet nas dinâmicas sociais do Tempo Presente e, consequentemente, os desafios que tal panorama vem apresentando para a história. Na realidade, os capítulos centrais do livro dialogam todo tempo entre si. Isto porque ambos vão tratar em maior ou menor escala das apropriações que grupos de extrema-direita têm feito da internet. Suas preocupações referem-se ao modo como, cada vez mais, a internet se apresen- 
ta como "uma espécie de novo oráculo, como um espaço autônomo do conhecimento" (p.43). Do deslumbramento com essa realidade, e do fato de a internet ser uma espécie de zona neutra, território sem lei, ele alerta que decorrem graves perigos. Um deles, senão o principal, é o tema da engajada exposição do autor no Capítulo 2: a facilidade de produção de suportes pedagógicos na rede mundial de computadores e sua apropriação por grupos ou indivíduos de extrema-direita.

Para lidar com história em meio à superinformação característica da world wide web, em plena 'Era Google', tomando emprestada a expressão de Carlo Ginzburg, ${ }^{2}$ toda cautela é pouca, pois, como nos diz o historiador italiano, "No presente eletrônico o passado se dissolve”. Como assim? O 'dissolver-se' de Ginzburg pode ser lido em muitas direções, uma das quais é a que diz respeito aos dilemas da memória e do esquecimento na rede, como e o que preservar dos arquivos digitais neste século XXI. Entretanto, a preocupação do nosso autor é mais específica. A 'dissolução' do passado, para Maynard, está nas possíveis manipulações da história que podem ser feitas na internet. Uma das evidências desse problema, para ele, são os espaços virtuais destinados a servir de suportes pedagógicos para projetos de doutrinação, alguns deles comprometidos, por exemplo, com retóricas revisionistas. Tais iniciativas pretendem fazer reconstruções historiográficas, tentam estabelecer falsificações e forjar narrativas que classifiquem, por exemplo, as memórias sobre o Holocausto e a Segunda Guerra Mundial como meras conspirações. Ele chama a atenção:

Em inversões interpretativas, os algozes são vítimas, qualquer tipo de documentação que evidencie tortura, prisão, assassinatos e a racionalização das mortes em campos de concentração e câmaras de gás é descartada como 'falsificação' ... Em meio a apropriações simbólicas e batalhas da memória, estes portais são exemplos de ferramentas eletrônicas dedicadas a promover uma leitura intolerante da história sob pretensa pátina de luta por liberdade de expressão. (p.45)

Dentre as tentativas de reescrita da história, um dos casos destacados pelo autor é o do portal Metapedia, ${ }^{3}$ autodenominado 'enciclopédia alternativa', que traz, entre outros, verbetes sobre líderes e representantes da extrema-direita, em que estes são apresentados sem nenhuma menção aos seus xenofobismo ou racismo. Mesmo o führer nazista, Adolf Hitler, é descrito com benevolentes esquecimentos. Fica para a nossa reflexão a importância de um 
inventário, como esse que empreende Maynard, de ódios e revisionismos soltos pela rede. Se não nos ocuparmos deles, a quem os delegaremos? Às inteligências estatais ou às polícias? Mas, e pela história, quem fará vigília?

Cabe lembrar que essa batalha das memórias e dos lugares de memórias é atualíssima e extrapola as fronteiras do ciberespaço. É importante ressaltar, portanto, que apesar dos limites dessa obra, o esforço que nela se faz para advogar em favor da sistemática investigação histórica do e no ciberespaço, embora se baseie majoritariamente em exemplos e documentações disponíveis na própria rede, guarda estreita relação com a realidade 'não virtual'.

A intolerância promovida na rede por grupos extremistas como os skinheads, os carecas paulistas e outros, desgraçadamente faz vítimas reais para além dos frios números de audiência que podemos verificar em web-estatísticas. O alcance das páginas de ódio, como o www.radioislam.org, o www.ilduce.net e o www.valhalla88.com, ${ }^{4}$ ou ainda o www.libreopinion.com (infelizmente os exemplos são vastos e de várias nacionalidades), é grande. E como lembra o título do terceiro capítulo, esses sites não trabalham isolados, em muitos casos se montam verdadeiras 'Redes de Intolerância', com troca de links, apoio 'cultural' (pela troca de banners etc.) e mesmo assistência mútua em caso de um site precisar ser hospedado em outra 'casa' para poder fugir ao rastreamento da polícia. Organizados e rápidos, eles conseguem escapar mais facilmente das investigações e das consequências, graças à transnacionalidade do mundo virtual, que permite, em certos aspectos, essa "anomia geográfica" (p.103-104), e assim prorrogam indeterminadamente a impunidade dos integrantes desses grupos. O que mais precisamos viver para lembrar o fascismo? Se a resposta for neofascismos, aí vamos nós. Preparem suas mentes, corações e hard disks para o caso de carregamentos muito pesados: xenofobia, machismo, homofobia, misoginia, racismo... eugenias.

Por fim, Maynard nos introduz no fantástico campo do 'ciberativismo' ou 'hacktivismo'. Temas por onde esbarraremos também com os profissionais de Relações Internacionais preocupados com a diplomacia clássica em crise (será?) em tempos daquilo que algumas nações vêm chamando de 'ciberguerra' (guerra de informação) ou ainda ciberterrorismo. O autor demonstra como os Estados Unidos se apropriaram dos escândalos midiáticos referentes ao Cablegate ${ }^{5}$ para alimentar uma interpretação belicista do momento, condenando as denúncias do Wikileaks e os atos de protestos do grupo de hackers 
Anonymous em 2010 como terrorismo. Para Maynard, o perigo dessa manipulação de opinião a partir de apropriações políticas do ativismo cibernético é a criação de uma atmosfera promissora para um "indesejável remake dos dias da Guerra Fria” (p.141). A saber, com quais intencionalidades políticas, a troco de que esquecimentos...

Os problemas expostos nesse livro nos remetem a vários estudos sobre história e internet, ou, como já batizaram alguns estudiosos, 'Historiografia Digital'. Todos, contudo, bastante recentes e também marcados, uns mais, outros menos, por uma levada introdutória, da apresentação de problemas e tímidas formulações de hipóteses, em virtude da relativa novidade do tema. ${ }^{6}$ Entretanto, pensando especialmente nas variantes ética, moral e política da história, gostaríamos de fazer referência aqui ao trabalho do historiador francês Denis Rolland, que, assim como Maynard, também entende a internet como uma nova fonte e objeto para a história, inscrita no Tempo Presente e demandando cautelosos e redobrados exames críticos. Para Rolland, na rede, a história assume frequentemente a forma de narrativas de 'costuras invisíveis', cujo nível de credibilidade científica é quase sempre desconhecido ou inverificável, o que pode acabar levando a um 'mal-estar da história', por ser, muitas vezes, repleta de dissimulações ou amnésias-construtivas, uma "história sem historiador", 7 exposta, portanto, aos riscos de reconstruções historiográficas tal qual nos adverte Maynard no Capítulo 2 (p.43-66). É por tudo isso que, como afirma o autor já no início do livro, "pesquisar a história da internet, assim como navegar, é preciso" (p.42).

\section{NOTAS}

${ }^{1}$ LARROSA, Jorge. Linguagem e educação depois de Babel. Trad. Cynthia Farina. Belo Horizonte: Autêntica, 2004. p.7.

${ }^{2}$ GINZBURG, Carlo. História na Era Google. Fronteiras do Pensamento, 29 nov. 2010. (Conferência). Disponível em: www.youtube.com/watch?feature=player embedded\&v=wSSHNqAbd7E (Vídeo); Acesso: 22 mar. 2012.

${ }^{3}$ Página da 'enciclopédia' em Português: pt.metapedia.org/wiki/P\%C3\%Algina_principal; Acesso em: 23 mar. 2012.

${ }^{4}$ Cujo conteúdo hoje se encontra disponível em outro endereço: www.nuevorden.net/portugues/valhalla88.html; Acesso em: 23 mar. 2012. 
${ }^{5}$ Termo cunhado pela imprensa mundial para nomear o escândalo gerado pelo site Wikileaks ao divulgar centenas de documentos e telegramas 'secretos' de autoridades da diplomacia norte-americana sobre vários países.

${ }^{6}$ Para uma apreciação mais detida dos problemas de ordem teórico-metodológica na relação entre história e internet, sob o ponto de vista da Historiografia Digital, ver: COHEN, Daniel J.; ROSENZWEIG, Roy. Digital History: a guide to gathering, preserving, and presenting the past on the web. Philadelphia: University of Pennsylvania Press, 2006. Disponível em: chnm.gmu.edu/digitalhistory/; Acesso em: 22 mar. 2012; RAGAZZINI, Dario. La storiografia digitale. Torino: UTET Libreria, 2004. Em língua portuguesa, ver: LUCCHESI, Anita. Histórias no ciberespaço: viagens sem mapas, sem referências e sem paradeiros no território incógnito da web. Cadernos do Tempo Presente, ISSN 2179-2143, n.6. Disponível em: www.getempo.org/revistaget.asp?id_edicao=32\&id_materia=111; Acesso em: 23 mar. 2012.

${ }^{7}$ ROLLAND, Denis. Internet e história do tempo presente: estratégia de memória e mitologias políticas. Revista Tempo, Rio de Janeiro, n.16, p.59-92. jan. 2004. p.2. Disponível em: www.historia.uff.br/tempo/artigos_dossie/artg16-4.pdf; Acesso em: 23 mar. 2012.

Resenha recebida em 20 de janeiro de 2012. Aprovada em 26 de março de 2012. 